\title{
OSTEOMYELITIS IN THE SPINAL CORD INJURED: A REVIEW AND A PRELIMINARY REPORT ON THE USE OF HYPERBARIC OXYGEN THERAPY
}

\author{
By I. Eltorai, M.D., G. B. Hart, M.D., Michael B. Strauss, M.D. \\ The Spinal Cord Injury Service, Veterans Administration Medical Center, 590I \\ East Seventh Street, Longbeach, 90822 California, USA.
}

Summary. Spinal Cord Injury patients are liable to develop osteomyelitis mostly by extension from pressure ulcers. In 2055 records reviewed in the Long Beach Spinal Cord Injury Service of the Veterans Administration Medical Center, the incidence was found to be 4.3 per cent. Of these osteomyelitis developed secondary to pressure ulcers in 88 per cent, the rest developed as a result of trauma and/or surgery. Forty-four patients manifesting chronic osteomyelitis were treated in a monoplace hyperbaric oxygen ( $\mathrm{HBO}$ ) chamber, in addition to receiving antibiotic and surgical treatment. HBO was found useful as an adjunct to help to resolve the bone infection and encourage wound healing. Two-thirds of the patients were cured, and the follow-up was from 6 months to 9 years. We believe that HBO is a useful adjunctive therapeutic measure in the management of chronic osteomyelitis in the spinal cord injured and in the prevention of its complications.

Key words: Spinal cord injured patients; Osteomyelitis; Hyperbaric oxygen therapy; Antibiotic therapy; Surgical treatment.

\section{Introduction}

SPINAL CORD INJURY (SCI) was recorded from the earliest records of civilisation. The Edwin Smith Papyrus (Breasted et al., I 930), written about 5000 years ago, contains a clear description of the cardinal symptoms of a complete lesion of the spinal cord following a neck injury. In the same papyrus, considered as the first textbook of surgery, the oldest known records of bone diseases are found. Open fractures and the draining of bones were treated as inflammatory diseases using a pharmacopoea of plant and animal extracts, as well as by splinting. In spite of the antiquity of both spinal cord injury and osteomyelitis, the incidence of osteomyelitis in SCI patients has not been well documented, but according to Eltorai (I98I) it occurs in about 5 per cent of such (SCI) patients. It most commonly affects the hips, the ischia, the sacrum and the calcaneous, in descending order of frequency. Less common sites are the ankle, the knee, the elbow, and lumbar vertebrae. It is rarely seen in the toes, metatarsals, tibia, fibula and the ulna. Staphaylococcus aureus had been the predominant organism. The radiological signs have been observed in the majority of cases in the form of osteoperiostitis, bone destruction, sequestration, pathological dislocation of joints and occasionally pathological fractures of a long bone.

This paper discusses the aetiology and pathophysiology of chronic osteomyelitis in SCI patients, and reviews the treatment of this condition in 44 cases treated by the conventional methods of surgery and antibiotics; but in addition by hyperbaric oxygen therapy. This is the first report of 
our experience using hyperbaric oxygen for the treatment of chronic osteomylitis in SCI patients.

\section{Aetiology}

Osteomyelitis in SCI patients is called 'transferred osteomyelitis' (Burri, I975). The most common predisposing factor is a pressure ulcer. In 88 per cent of our series, the infection spread from the infected pressure ulcer to the underlying bone (Eltorai, I98I). Pressure sores are the end result of tissue ischaemia due to pressure and/or shearing forces with consequent necrosis and bacterial invasion. The fourth, or deepest degree of ulceration, may involve the underlying periosteum (periostitis) or the cortex (osteitis) or the whole thickness of the bone, causing osteomyelitis. Bone infection occurs after there is bacterial invasion of the skin, subcutaneous fat, muscles, tendons, ligaments and bursae.

In 12 per cent of the cases studied (Io patients) other causes of osteomyelitis include trauma to the paralysed extremities with or without open fractures (6 cases). It is known that open reduction with or without internal metallic fixation is liable to be complicated by osteomyelitis in SCI. There is a 65 per cent incidence of osteomyelitis in open fractures in general (Waldvogel, I970). Other infrequently encountered causes (of which we had none), include puncture wounds, and animal and human bites. Failed amputations constituted another cause of osteomyelitis in our series (4 cases). All patients in this group had peripheral obliterative arterial disease; three with Leriche's Syndrome. Haematogenous osteomyelitis, which is the common cause in non-Spinal Cord Injured, (Resnick and Niwayama I98 I), was not observed in this group of patients. The course of the disease is usually chronic, but subacute cases and acute septicaemic cases have been encountered. Septicaemia in these patients is secondary to bone and/or joint infection from a pressure ulcer, especially in the diabetic and the malnourished.

\section{Material}

Of 2055 patients reviewed at the Spinal Cord Injury Service of the Veterans Administration Medical Centre at Long Beach, California, 90 patients had osteomyelitis; that is, an incidence of 4.3 per cent (Eltorai, I98I). The majority had the chronic variety. Forty-four (49 per cent) of the 90 patients received adjunctive hyperbaric oxygen therapy; they were all spinal cord injury patients. One patient, in addition, had multiple sclerosis. Ages ranged from 24-83 years. All patients were males. Thirty of the patients had paraplegia and 14 had tetraplegia. The onset of the osteomyelitis was I-30 years following injury. In the majority of the patients with osteomyelitis the infection involved the pelvis or the lower extremities. Table I lists the sites of involvement. Seven patients had more than one focus of osteomyelitis (I6 per cent).

The bacteriological findings from the sinuses, wounds and bone cultures usually showed mixed flora. Staphylococcus aureus was cultured in almost IoO per cent of the cases. It was either the predominant organism or was associated with a mixed flora. Other organisms cultured included the streptococcus group in 33 per cent Pseudomonas aerogenosa in 66 per cent, Proteus 
TABLE I

Sites of chronic osteomyelitis in 44 patients $(7(16 \%)$ had more than one focus)

\begin{tabular}{lcc}
\hline Site & Number & $\begin{array}{c}\text { Percentage } \\
\%\end{array}$ \\
\hline $\begin{array}{l}\text { Hip regions; i.e. hip joints, } \\
\quad \text { upper femora, trochanters }\end{array}$ & 28 & 64 \\
$\begin{array}{l}\text { Pelvis (I ilium, 4 ischium \& } \\
\quad \text { I os. pubis) }\end{array}$ & 6 & I 4 \\
$\begin{array}{l}\text { Lumbar spine } \\
\text { Sacrum }\end{array}$ & 3 & 7 \\
Knee joint & 5 & I I \\
Tibia & 2 & 4 \\
Elbow & 2 & 4 \\
& 4 & 8 \\
\hline
\end{tabular}

group in 33 per cent, Enterococcus in 42 per cent, E-Coli in 2 I per cent, and other organisms in 8 per cent (e.g. Klebsiella, Providencia, and Serratia). Diptheroids were detected in almost half of the cultures.

Radiological signs of osteomyelitis were evident in 86 per cent of the patients. These were mostly areas of destruction, radiolucent areas, irregularities, cavitation, periosteal reaction and rarely sequestration. The Technitium diphosphonate bone scan was almost uniformly positive for increased perfusion and osteoblastic activity. Correlation of the scans with $\mathrm{X}$-ray findings is important since the presence of a pressure ulcer usually increases the isotope uptake in that area. A Gallium scan was resorted to in some cases, to confirm the diagnosis. Computerised axial tomography has not been used, although it may provide further information, Firooznia et al. (I982). Tomography was done in some cases to delineate the extent of the bone damage.

Ten different complications of chronic osteomyelitis in patients with spinal paralysis were encountered. They ranged from a contagious septic arthritis to malignant degeneration. Table II lists these complications.

TABLE II

Complications of osteomyelitis

I. Spread to the neighbouring joint (septic arthritis).

2. Spread to soft tissues: cellulitis and suppuration.

3. Persistent sinuses and ulceration.

4. Systemic sepsis causing shock, that may be fatal.

5. Pathological fracture and/or dislocation mostly seen in the hip region.

6. Bone marrow depression with anaemia and leucopenia.

7. Protein depletion associated with large pressure ulcers and especially in the depressed anorexic patient.

8. Amyloidosis with renal failure.

9. Nephrotic syndrome not necessarily resulting from amyloidosis.

Io. Malignant change (cancer). 
The most serious complication in the acute stage is septicaemia with septic shock. In the chronic stage the most serious complications are amyloidosis and cancerous degeneration. In our centre, 75-80 per cent of patients who had died from renal failure and had had an autopsy showed amyloidosis from various causes, including osteomyelitis (Vaziri). In the last Io years, four patients have been found to have malignant (cancerous) changes (Eltorai, I98I).

\section{Therapy}

Conventional measures of surgery and antibiotic treatment were used as indicated by the pathology of the infection and the bacteriological findings. Antibiotic treatment was used in consultation with an infectious disease specialist, and usually lasted from 3-6 weeks and was given by parenteral routes, usually intravenously. One or more antibiotic was given, depending on the organisms and their sensitivity. The common antibiotics used were: Naficillin, Cephalosporins, Penicillin, Gentamicin, Amikacin and Carbenicillin. Tetracycline was given orally for I week pre-surgery to tag the bone which was observed under ultra-violet light in the operating room to distinguish the disease from the healthy bone during ostectomies. Surgical treatment varied according to the needs of individual patients. Procedures used included; incisions and drainage, debridement of soft and hard tissues, partial ostectomy, total ostectomy, sequestrectomy, planification, and filling cavities with muscle grafts. Bone grafting was not done. Amputation was required in five patients when less radical therapies failed and especially when there was co-existing peripheral vascular disease. This was only seen in the lower extremities.

Wound treatment requires dressing changes three times a day. Local antibiotic irrigation was not used because of the risk of bacterial resistance. Povidine-iodine was used with great caution in patients with renal failure since it may precipitate uraemic symptoms (Aronoff, I980). Dakin's Solution, Ringer's Solution, or normal saline were the most frequently used solutions for the change of dressings. Gentamicin polymethylmeth-acrylate (PMMA) beads, as recommended (in the Amsterdam Symposium) were not used, but are being considered (Van Rens and Kayser, I98I). Pure hyperbaric oxygen (HBO) was used at 2 ATA (atmospheric) pressures for 2 hours daily in Monoplace Chambers. The number of treatments ranged from 30-70 sessions; the average number was 50. No significant side effects of the hyperbaric oxygen were observed, such as seizures or pulmonary $\mathrm{O}_{2}$ toxicity. Several patients experienced minimal middle ear barotrauma experienced as pain. One patient required myringotomy to allow him to continue with his hyperbaric treatments; the myringotomy healed spontaneously after terminating the hyperbaric oxygen therapy. Only one patient in the series developed claustrophobia so that his treatment schedule required to be modified.

\section{The Role of Hyperbaric Oxygen Therapy}

The role of hyperbaric oxygen therapy in chronic refractory osteomyelitis has been reported by various authors (Bingham and Hart, I977; Evans, I976; Strauss, I980; Mader, I98 I; Morrey, I979; Depenbush et al., I972). 
The possible mechanism of hyperbaric oxygen is chronic refractory osteomyelitis is summarised as follows:

I. Facilitation of the host defense responses: High oxygen tension favours the leucocyte killing mechanisms that are oxygen dependent through hydrogen peroxide and superoxide production. Osteomyelitis is known to be hypoxic. Hyperbaric oxygen by itself has been demonstrated to be as effective as cephalosporins in controlling induced staphylococcal osteomyelitis in the animal model (Mader, I978).

2. Hyperbaric oxygen promotes neovascularisation of ischaemic osteomyelitis. Once circulation is improved, antibiotics, leucocytes and antibodies can be delivered more readily and effectively to the infection focus (Halasz, I966).

3. Hyperbaric oxygen enhances osteoclastic activity to remove bony debris and dead infected bone. Through neovascularisation and osteoclastic hyperactivity, the ischaemic interface between the host and the septic focus is dissolved, thus facilitating the effects of the leucocytes, antibodies, and antibiotics. This may be the most important rôle of hyperbaric oxygen in chronic osteomyelitis. In the absence of ischaemia, HBO may be of little or no value, and may even have deleterious effects on osteogenesis and bone healing (Shaw and Bessett, I967). Experiments and human studies show conclusively that $\mathrm{HBO}$ promotes wound healing when healing is delayed because of ischaemia and infection (Eltorai, I98I).

4. The direct effect of $\mathrm{HBO}$ on bacteria, specifically anaerobes and microaerophilics, is probably insignificant in chronic osteomyelitis. These organisms are rarely found in chronic osteomyelitis. Faculative aerobes like Staphylococci and gram negatives are only inhibited by oxygen pressures so high that they are unsafe for human treatments.

\section{Results}

Out of 44 patients, 30 (68 per cent) were considered cured, i.e. their wounds healed without the necessity for drainage, with follow-up studies from 6 months to 9 years. The highest cure rates were in spinal osteomyelitis, in which all were cured; and the elbow, in which 3 out of 4 patients were cured. Recurrence occurred in five patients (I I per cent) with sinus formation that required excision and curettage of the bone in three and a Girdlestone Procedure in the fourth. This was combined with antibiotics and a repeated course of $\mathrm{HBO}$, and resulted in arrest of the infection. The fifth patient succumbed because of chronic renal failure. All recurrences were of osteomyelitis in the hip region. In one, heterotopic bone resection was performed during debridement. There were nine failures ( 20 per cent); 6 (67 per cent) were due to vascular occlusive desease including Leriche's Syndrome (3), and iliofemoral block (3). One of the latter patients had a thrombosed ilio-femoro-popeiteal bypass. Five of those with vascular disease required thigh amputation. One developed osteomyelitis of the stump and died of renal failure after reamputation. One of the failures was due to osteomyelitis of the ilium secondary to pressure ulcers after a 
hip disarticulation 25 years earlier; malignant changes (cancer) occurred in the chronic ulcer of this patient, and he died from abdominal and hepatic metastases. Another failure occurred in a patient who refused to cooperate fully with the treatment programme (osteomyelitis of the elbow); he subsequently died in a motor vehicle accident. The last failure was due to septicaemia from soft tissue gangrene. Thus, seven of the nine failures (78 per cent) had osteomyelitis involving the lower extremities, in two-thirds of them there was vascular obliterative disease, one localised in the ilium who developed cancerous changes, and another localised in the elbow (the one who did not cooperate with his treatment).

\section{Discussion}

Osteomyelitis in spinal cord injury (SCI) patients is usually due to extension of the infection from pressure sores and is usually chronic. Management of osteomyelitis in SCI patients must be directed towards a cure to reduce the chance of chronic infection which can lead to amyloidosis, especially when associated with chronic genito-urinary infection. Both result in renal failure, which is the most cusimon cause of death in the spinal paralysed patient (Guttmann, I976; Tribe, I963; Tribe and Silver, I969; Talbot, I976; Nyquist, I960). Seventy-five-80 per cent of the SCI patients dying from renal failure had evidence of amyloidosis (Vaziri).

In general, the standard technique for excision of the pressure ulcer and the infected underlying bone, together with the use of appropriate antibiotics, have given satisfactory results in the majority of cases. HBO has been especially useful as an adjunct to treatment for the following indications:

I. When complete removal of the infected bone is not recommended, as in bilateral osteomyelitis of the ischium; because after a bilateral ischiectomy, pressure on the bladder base and the urethra leads to diverticulosis and urinary fistula formation (Comarr, Eltorai et al., in Press).

2. In irremovable bones such as lumbar vertebrae, the sacrum, and the ilium, and in septic arthritis of large joints, especially of the upper extremities where amputation is objectionable.

3. In osteomyelitis complicating surgery following the insertion of metal prostheses, or as sequel to resection of heterotopic ossification.

4. In traumatic osteomyelitis as an adjunct to antibiotics and stabilisation.

5. Lastly, ischaemic random skin flaps that are used to cover pressure ulcer defects associated with osteoresection can be resuscitated by $\mathrm{HBO}$ in conjunction with other measures (Eltorai, I98 I). The same applies to ischaemic flaps after amputations in SCI.

As discussed under 'The Role of Hyperbaric Oxygen', the rationale for the use of $\mathrm{HBO}$ in chronic osteomyelitis exists and is particularly applicable to the spinal cord injured man because of the reduced host response defense and vascular responses.

It must be emphasised that $\mathrm{HBO}$ is used as an adjunct to medical, antibiotic therapy, and surgical intervention. The results indicate that twothirds of the patients can be cured. About io per cent had recurrences 
which could be controlled. Twenty per cent failed, usually from associated major vascular occlusion, cancer, and/or incomplete treatment. Our experience indicates that $\mathrm{HBO}$ can be a useful therapy in the management of chronic osteomyelitis in patients with spinal paralysis.

\section{RÉSUMÉ}

Les malades atteints de traumatisme de la móelle épiniere sont sujets à osteomyelite surtout par extension des escarres. Entre 2055 dossiers revues an Centre des paraplégigues de Veterans Administration à Long Beach $4.3 \%$ avaient l'osteomyelite. Chez quatre-vignt-huit pourcent l'osteomyelite etait en consequences des escarres.

En douze \% l'osteo etait en consequence de traumatisme ou postopératoirie. Quarantequatre malades portants de l'osteo chronique etaient traités avec l'oxygéne hyperbare tonjours avec le traitement antibiotique et chirugical. L'oxygéne hyperbare aidait la resolution de l'osteo chez 2/3 des malades avec un eguérison completé pendant 9 ans au 6 mois. Nour considerans le traitement hyperbare une therapeutique utiles de l'osteo chronique chez les paraplegigues et un moyen preventif de ses complications.

\section{ZUSAMMENFASSUNG}

Dié Paraplegiker sind haftbar für Knochen-entzunding. Zwichen 2055 patienten in Long Beach Zentrun der Parapligiker des Veterans Administration $4.3^{\circ}{ }_{0}^{\circ}$ hatten osteomyelitis; $88 \%$ denen durch Dekubitus in fektionen.

44 Patienten hatten Hyperbare sauerstaff Behandlung Kombriniert mit Antibiotika und Chirugie. Zwei drittel diesen Fällen volkoumen geheilt. Wir glauben dass Hyperbare Sauerstaff Behandlung ist nutzlich in Osteomyelitis der Paraplegiker.

\section{REFERENCES}

Aranoff, G. R., Friedman, S. J., Doedens, D.J. \& Lavelle, K. J. (I980). Increased serum iodine concentration from iodine absorption through wounds treated topically with povidone-iodine. Am. F. Med. Sciences, 279, 3, I73-176.

BINGHAM, E. I. \& HART, G. (1977). Hyperbaric oxygen treatment of refractory osteomyelitis. Postgrad. Med., 6I(6), 70-76.

Breasted, J. H. (I 930). 'The Edwin Smith Papyrus' published in fascimile and hieroglyphic transliteration with translation and commentary in two volumes. Univ. of Chicago Press. Chicago, Ill.

BURRI, Caius (I975). Post-traumatic Osteomyelitis. Hans Huber Publishers. BernStuttgart-Vienina, 83 .

Depenbush, F. L., Thompson, R. E. and Hart, G. B. (1972). Use of hyperbaric oxygen in the treatment of refractory osteomyelitis. A Preliminary Report. The F. of Trauma, I 2,9, 807-8I 2 .

EltoRAI, I. (I98I). Hyperbaric oxygen in the management of pressure sores in patients with injuries of the spinal cord. F. Dermatol. Surg. Oncol., 7:9, 739-740.

Evans, B. E., Jackobson, J. H., II, Pierce, E. C. II, Friedman, E. W. and Schwartz, A. E. (1976). Chronic osteomyelitis of the mandible. Hyperbaric Oxygenation Treatment. N. Y. State F. Med., 76(6), 966-967.

Firooznia, H., Rafir, M., Golimbu, C., Lam, S., Sokolow, J., and Kung, J. S. (I982). Computed Tomography of Pressure Sores, Pelvic Abscess, and Osteomyelitis in Patients with Spinal Cord Injury. Arch. Phys. Med. Rehabil., 63, 545-548.

GuttmanN, Sir Ludwig. (1976). Spinal Cord Injuries. Blackwell Scientific Publications. Oxford-London-Edinburgh and Melbourne, 45I.

Halasz, N. A., Stier, H. A., Seiffert, L. N. and Orloff, M. J. (i966). Antigen production in hyperoxic organ cultures. Prac. Soc. Exper. Biol. and Med., 122, 220-223.

MADER, J. T. (I98I). Phagocytic killing and hyperbaric oxygen: antibacterial mechanism. $H B O$ Review, 2, 27.

Mader, J. T. Guckian, J. C., Glass, D. L. and Reinarz, J. A. (1978). Therapy for experimental osteomyelitis due to staphylococcus aureus in rabbits. F. Infect. Dis., 138, 213-2I8. 
Morrey, B. F., Dunn, J. M., Heimbach, R. D., and Davis J. C. (1979). Hyperbaric oxygen and chronic osteomyelitis. Clin. Orthop. Rel. Res., II4, I 2 I.

Nyquist, R. H. (1960). Mortality in Spinal Cord Injuries, Preliminary Report. Proceedings of the Ninth Annual Clinical Spinal Cord Injury Conference. Veterans Administration Hospital, Long Beach, California, Oct. I 8-20, I09-I I 2.

Resnick, D. and Niwayama, G. (I98I). Diagnosis of Bone and foint Disorders. Vol. 3, 2042-2237, W. B. Saunders Philadelphia-London-Toronto.

Shaw, J. L. and BASSETT, C. A. (1967). The effects of varying oxygen concentrations on osteogenesis and embryogenic cartilage in vitro. F. Bone E foint Surg., 49A, 73-80.

Strauss, M. B. (I980). Chronic refractory osteomyelitis: review and role of hyperbaric oxygen. HBO Review, I, 23 I.

TAlBot, H. S. (I976). Cited by Guttmann, page 452 (see above).

Tribe, C. R. (I963). Causes of death in early and late stages of paraplegia. F. Paraplegia, I, I9-47.

Tribe, C. R. and Silver, J. R. (1969). Renal failure in paraplegia. Pitman Medical, London. VANRENS, TH. J. G., KAYSER, F. H. (I98I I). Local antibiotic treatment in osteomyelitis and soft tissue infections. Excerpta Med. Amsterdam-Oxford-Princeton.

Vaziri, N.: (Personal Communication).

Waldvogel, F. A., Medoff, G., and Swartz, M. N. (1970). Osteomyelitis, A review of clinical features, therapeutic considerations and unusual features. New Engl. F. Med., 292, 198 (Pt. I), 260 (Part II) and 316 (Part III). 